\title{
Desobediencia civil, feminismo y cuerpo
}

\author{
Rosalía ROMERO PÉREZ \\ Universidad de Sevilla \\ rosaliarom@gmail.com
}

Recibido: Mayo 2015

Aceptado: Junio 2015

\section{RESUMEN}

En el artículo se analiza la desobediencia civil feminista como hija de la democracia. A la luz del análisis de las distintas interpretaciones de los derechos naturales, se sigue la trayectoria que ha tenido el "derecho al propio cuerpo", desde el Sufragismo y su época hasta el mundo global. En el momento actual, el derecho al propio cuerpo es defendido desde posiciones enfrentadas como son Femen y el Feminismo Islámico.

Palabras clave: Desnudo femenino, desobediencia civil feminista, derecho a la propiedad del cuerpo.

\section{Civil disobedience, feminism and body}

\begin{abstract}
In this article, feminist civil disobedience is analysed as democracy's daughter. As regards the analysis of different interpretations of natural rights, the path of the ownership of the own body is followed from Sufragism and its epoch until the global world. At the present time, the right to own your body is defended from opposite positions, such as Femen and Islamic Feminism.
\end{abstract}

Keywords: Female nude, civil disobedience Feminist, right to the ownership of the body.

\section{INTRODUCCIÓN}

La desobediencia civil y el Sufragismo nacieron en el siglo XIX, y en ambos casos su esencia radicó en visibilizar y denunciar las carencias de la democracia representativa. La democracia moderna, aunque se diferenciaba de la democracia griega en que no era directa, excluía de igual modo a los esclavos y a las mujeres de los derechos de ciudadanía. Tanto la Revolución francesa como la Revolución americana adolecían de déficits democráticos, al repetir y redundar en el carácter excluyente que desde los Sofistas se criticara a la democracia ateniense. No obstante, malgré el conocido y venerado caso Sócrates y su condena a pena de muerte por la democracia griega, la desobediencia civil, desde su origen, no renunció a la democracia sino que planteó y exigió cuotas de mayor democracia. Y en este sentido, la desobediencia civil en su origen es la filosofía teórica y práctica que desvela las insuficiencias de la 
democracia representativa: las minorías numéricas y/o sociológicas reclamaban estar representadas en los espacios de lo político, al mismo tiempo que planteaban que la opinión de la mayoría no tiene que ser siempre la más justa.

La desobediencia civil, entendida como una de las maneras de regulación del Derecho, viene a plantear, de nuevo, el problema de la legalidad y la legitimidad. Por ello, las prácticas de desobediencia civil, abiertamente públicas, se fundamentan en un disentimiento básico, aportando a las teorías democráticas del Contrato Social una variable no contemplada en su seno y que, sin embargo, no por ello dejaba de existir en el espacio de lo social o de lo privado.

El Sufragismo es el primer movimiento social que practica la desobediencia civil utilizando el cuerpo: la huelga de hambre como método de lucha pacífica es un ejemplo. La carencia de referentes empíricos en la historia influyó, entre otros factores que hemos expuesto en la primera parte del artículo, para que la visión del cuerpo de las mujeres se alineara mayoritariamente en una tradición que, al mismo tiempo, posibilitó el diálogo con su época.

La desobediencia civil feminista en el siglo XXI presenta una novedad: tiene una historia y unos referentes en los que apoyarse. El Sufragismo y la Ola de feminismo que emerge en la década de los años setenta constituyen pilares ineludibles para entender la seguridad con la que las activistas de Femen plantean sus críticas al androcentrismo y patriarcalismo de la revolución sexual, al mismo tiempo que sus prácticas de desobediencia civil. De modo distinto tenemos que hablar de las mujeres musulmanas y su experiencia del cuerpo: la carencia de una genealogía en la que reconocerse lleva a las mujeres o bien a realizar nuevas exégesis del Corán, o bien a adoptar posturas vitales de índole mística o ascética. Existen, pues, dos formas de enfrentarse o de reaccionar frente al Patriarcado, como exponemos en la segunda parte de nuestro trabajo, invitando a una reflexión sobre qué medidas deben proponerse para una Europa democrática en la que el fenómeno Euroislam es una realidad que no tiene retorno.

\section{LA DESOBEDIENCIA CIVIL EN EL MARCO POLÍTICO DE LA DEMOCRACIA: EL SUFRAGISMO Y SUS REFERENTES}

\subsection{SOCIEDAD CIVIL EN EL PRIMER LIBERALISMO POLÍTICO}

La desobediencia civil es, históricamente, hija del pensamiento democrático. Es una expresión acuñada con posterioridad a las de sociedad civil, parlamentarismo, monarquía constitucional y separación de poderes. El filósofo ilustrado Jonh Locke legitimó con su obra el nacimiento de la monarquía constitucional, parlamentaria y representativa, cuyos poderes legislativo y ejecutivo crearían y llevarían, respectivamente, a la práctica las leyes, estando éstas por encima del monarca. En su Tratado sobre el gobierno civil estableció que los derechos naturales reconocidos a todos y a cada uno de los individuos de la especie humana, derecho a la vida, derecho a la libertad y derecho a la propiedad habrán de ser protegidos por las leyes y, en el caso de que no se cumplan, cabrá la posibilidad de recurrir; sólo bajo esta condición existirá 
la sociedad civil, habida cuenta de que al poder apelar a una autoridad conocida, y establecida por consenso, cada uno de los individuos ha cedido previamente su poder a los cuerpos políticos creados. Locke, tras cuestionar que la monarquía absoluta fuera el único tipo de gobierno posible en el mundo, afirma que la sociedad civil tiene como finalidad evitar los inconvenientes del estado de naturaleza, porque "cada uno está obligado, por consentimiento, a someterse al parecer de la mayoría (...) y a ser guiado por ella” (Locke, 1990: 105). El pacto que cada uno realiza con el resto de los individuos en la formación de la sociedad civil tiene carácter de Contrato Social, siendo éste roto cuando un individuo no obedece las decisiones de la mayoría y vuelve a su estado asocial de naturaleza.

Además de señalar la importancia que tiene la noción de sociedad civil desde los inicios de la construcción de las sociedades democráticas modernas, destacaremos que Locke planteó la necesidad de que se les reconociera el derecho sobre sus hijos a las madres, y que el poder de los padres -padres y madres- debe ir encaminado a cuidar y educar a su descendencia: su labor consistiría en proveer de fuerza sus cuerpos y en dar vigor a sus almas para que los hijos e hijas sean útiles a sí mismos/as y a los demás. El recurso a los textos sagrados de la Biblia para apoyar su argumentación es una característica a tener en cuenta, no sólo porque se hacía necesario al rebatir el origen divino del poder -tesis defendida por sus referentes polémicos-, sino porque constituye una característica de la defensa de la Igualdad democrática en sus distintas versiones: en el primer Liberalismo, en el Movimiento Antiesclavista y en el Sufragismo

Con lo explicado de forma muy sumaria nos encontramos con los cimientos del Liberalismo político y, al mismo tiempo, con los primeros pilares del Estado de Derecho. Pero también nos encontramos con sus fisuras y vulnerabilidad: la representatividad, la cuestión de las mayorías y de las minorías, ya sean estas últimas minorías numéricas o grupos excluidos del Contrato Social y del Pacto.

\subsection{EL INDIVIDUO Y LAS LEYES}

La expresión "desobediencia civil” se la debemos a Henry David Thoreau por su opúsculo Del deber de la desobediencia civil, publicado en 1849. Este pensador estadounidense reconocía explícitamente que el progreso desde una monarquía absoluta a otra de carácter limitado, refiriéndose a la monarquía constitucional, fue un avance hacia el respeto por el individuo. Sin embargo, Thoreau se preguntaba si la democracia, tal y como era conocida a mediados del siglo XIX, era el mejor de los gobiernos posibles (Thoreau, 1849: 46), dado el carácter excluyente y la pseudorrepresentatividad. Thoreau se sumó a la lucha abolicionista: pasó una noche en la cárcel por negarse a pagarle un impuesto de capitación al gobierno de Estados Unidos, argumentando que su negativa se debía a que la esclavitud era legal en su país. La publicación de su obra cobra un sentido adicional en el contexto de la presión ejercida al gobierno de Estados Unidos, inmediatamente después de que hubiera sido abolida la esclavitud en Francia, con la Constitución de 1848.

Thoreau era consciente de cómo el Estado percibía a los esclavos y, por ello, en su obra utiliza el concepto de "masa” y el término "máquinas" para referirse a sus cuerpos. El mecanicismo objeto de crítica se refiere a la percepción y el uso y abuso 
que el Estado hace de lo que para él es una gran masa. La crítica a la relación mecanicista del Estado con los individuos concretos es contundente: la gran masa sirve al Estado como máquinas, con su cuerpo (Thoreau, 1849: 17). El Estado se enfrenta contra los cuerpos de los individuos y contra sus sentidos, utilizando la mayor fuerza física posible. "El Estado no se enfrenta nunca intencionalmente contra el sentido del hombre, intelectual y moral, sino contra su cuerpo, sus sentidos. No se arma de honestidad o de ingenio superior sino de mayor fuerza física” (Thoreau, 1849: p. 34).

La crítica de Thoreau se centra en el trato del Gobierno para con los individuos que están excluidos del Contrato social, percibidos y tratados como cuerpos productores. Efectivamente, los esclavos realizaban un trabajo muy productivo en los Estados Unidos en las plantaciones de algodón, permitiendo con ello las grandes exportaciones hacia Europa. Y dado que la mano de obra era realizada por esclavos y esclavas, las ventas de algodón en Europa se hacían a muy bajo coste, con el consiguiente auge de la producción textil de las prendas de algodón en el viejo continente, entre cuyos países importadores se encontraba Francia. Una novela de la época, La cabaña del tío Tom de Harriet Beecher Stowe, refleja la violencia de la que eran objeto los esclavos y el desempeño de su trabajo en las plantaciones algodoneras: Tom murió tras una paliza que recibió por ayudarle a una esclava a cargar unas pacas de algodón. Thoreau denunció la violencia contra los cuerpos productores pero no vio la violencia y exclusión de quienes eran percibidas como cuerpos reproductores. Al igual que los esclavos, las mujeres estaban excluidas del Contrato social y la violencia vertida contra ellas, cuerpos reproductores, se ejercía bajo formas específicas aunque la causa abolicionista y la causa feminista fueran de la mano en momentos muy importantes de sus respectivas luchas.

La percepción de las mujeres como cuerpos reproductores es muy longeva, y forma parte también del acervo cultural occidental que institucionalizó la separación de alma y cuerpo, identificando alma con pensamiento y racionalidad. En los hitos culturales más importantes de la tradición, instituidos como modelos de referencia, se encuentran dadas las pautas con las que se identifica una cultura. Lo que es importante, lo que los miembros de una cultura deben tener siempre presente nos es dado al mismo tiempo: el respeto a las leyes, aunque sean injustas, y la exclusión de las percibidas como cuerpos reproductores de las importantes tareas del Pensamiento. Un ejemplo muy ilustrativo es Sócrates en la democracia ateniense. El filósofo fue condenado a pena de muerte por los jueces, tras ser acusado de no reconocer a los dioses protectores de la ciudad-estado y de corromper a los jóvenes discípulos que le seguían, de corromperlos por enseñarles a pensar. Sócrates eligió respetar las leyes que el exilio o una vida clandestina. Se debía a sí mismo, tanto como a los ciudadanos a los que dirigió su discurso antes de tomar la cicuta para morir. Su actitud se derivaba de la defensa de su pensamiento, como una actividad fundamental, para que mereciera la pena su propia vida: pensaba que es mejor padecer el mal que ser causante del mismo. Era mejor para él, pero en el sentido de que no quería estar, cuando se encontrara solo, en desacuerdo consigo mismo. En el Teeteto, explicando el método que utilizaba para hacer pensar a los jóvenes, la mayéutica, Sócrates explica que el diálogo consigo mismo que supone pensar, consiste en todo momento en un examen del alma, y no del cuerpo. Y, dado el significado de "maio" en griego, dar a luz, afirma sin paliativos que, 
a diferencia de las parteras, él asiste a los hombres y no a las mujeres (Platón, 2003: 155).

La crítica al dualismo filosófico que separa alma y cuerpo, como si fueran dos existencias independientes la una de la otra, es cada vez más compartida en la Teoría Feminista. Pero más allá de esta visión crítica al dualismo antropológico, se ha centrado el análisis en ver cómo se ha generado la exclusión del mundo del pensamiento y de la búsqueda de verdades como una tarea propia de la cultura; y no sólo característica de lo humano sino de las peculiaridades más excelsas que se pueden encontrar en la especie. El pensamiento socrático y su manera de discernir en el Teeteto es ilustrativa de la universal forma de excluir a las mujeres del logos: definirlas como seres confinadas al ámbito de la reproducción de la especie. Y al estar confinadas a este ámbito se las percibe como más cercanas, que sus homólogos varones, a la naturaleza. A ello añadido que, en virtud del dualismo antropológico de la tradición occidental hegemónica, se considera que las mujeres son, sobre todo, seres humanos determinadas por su cuerpo. Ello explica que lo que Alison Jaggar ha denominado somatofobia se halla traducido en muchas ocasiones en misoginia (Jaggar, 1983: 186 y ss.).

\subsection{DISTINTAS CONCEPCIONES DE DESOBEDIENCIA CIVIL}

Entre la amplia gama de estudios sobre desobediencia civil en los textos éticopolíticos del pensamiento contemporáneo se encuentra la negativa a reconocer a Thoreau como un desobediente civil. Hanna Arendt considera que para Thoreau, en la misma medida que para Sócrates, el acuerdo con los otros/as es secundario con respecto a sus solitarias decisiones, como si lo que tuvieran en común con los otros/as fuera una conciencia, y no un criterio o una opinión (Arendt: 1998: 68); por ello, Thoreau no defendió su posición basándose en la relación moral de un ciudadano con la ley, sino en la conciencia individual y en la obligación moral de la conciencia. Arendt sostiene que la conciencia es apolítica porque "no se halla fundamentalmente interesada en el mundo donde se cometen los males o en las consecuencias que tales males tendrán para el curso futuro del mundo" (Arendt, 1998: 69).

Los dos argumentos que Arendt esgrime para explicar por qué la acción de Thoreau no es desobediencia civil, ser una acción individual y pertenecer al orden de la conciencia y, por tanto, ser apolítica, no pueden ser asumidos en un análisis políticofeminista sobre la desobediencia civil. Si bien, de acuerdo con Arendt, la desobediencia civil implica una teleología, mejorar las condiciones de existencia, como mínimo, de un grupo humano, la filosofía feminista no puede aceptar, sin entrar en discusión, que el ámbito de la conciencia es apolítico porque la conciencia supone la autoconciencia, y la autoconciencia es condición de posibilidad transformadora. Del mismo modo, no puede aceptar tampoco como criterio válido para definir y legitimar la desobediencia civil, excluir todas las acciones individuales, publicitadas in situ o no, que desobedezcan las leyes, porque fugarse de un harén o fugarse para que no te practiquen la ablación del clítoris no deben conllevar la publicidad en el momento mismo de la acción, sino que el hecho debe publicitarse con posterioridad a la desobediencia a la ley, positiva o consuetudinaria. 
La acción que, a mitad de siglo XIX, la sufragista estadounidense Lucy Stone y Henry B. Blackwell llevaron a cabo el día en que contrajeron matrimonio no fue colectiva, no eran un grupo de matrimonios: expresaron que no obedecerían las leyes implantadas para la mujer casada. En la ceremonia de su boda fue leído el manifiesto en el que se enumeraban cada una de las cláusulas de las leyes, para las mujeres casadas, que no cumplirían. La reclusión de la mujer al ámbito privado también fue objeto de rechazo por parte de la sufragista Lucy Stone en otro escrito, quien comprendió que tal reclusión estaba inextricablemente relacionada con prescripciones morales y pautas de conducta para los cuerpos femeninos: "No sé lo que vosotros pensáis de Dios. Yo creo que si nos dio deseos e ilusiones es para que fuesen satisfechos, pero que no tuvo la intención de que dedicásemos todo nuestro tiempo $a$ alimentar y vestir el cuerpo" (la cursiva es nuestra) (Martín Gamero, 2002: 58). Sin lugar a dudas, Lucy Stone estaba criticando un sistema social y político que confinaba a las mujeres al ámbito de la reproducción, y más allá incluso de la crítica al Patriarcado del siglo XIX, que reestablece la rigidez de fronteras entre lo privado y lo público, se puede leer en las palabras de Stone una crítica a una realidad que por los mismos años en que nació el Sufragismo se estaba implantando: el mundo de la moda femenina.

Los criterios establecidos por HannaArendt no validan la actuación de Stone y Blackwell como desobediencia civil, no sólo porque no sea una acción colectiva sino porque Arendt no considera que los asuntos privados y personales sean políticos. El término utilizado en su obra para referirse a las necesidades del cuerpo, y a todo lo que tiene que ver con el ámbito de la reproducción, es labor, que se contrapone al mundo del trabajo y, también, al mundo de la acción; esta última es considerada la esfera de la acción política por antonomasia (Arendt, 2011: 75 y ss.). La dimensión social no es considerada por Arendt como la propiamente humana porque es compartida con otras especies animales. Desde la década de los años setenta del siglo XX, cuando el eslogan "Lo personal es político" inspira a la Teoría Feminista y enriquece el análisis político con términos o conceptos tales como "violación en el lecho conyugal", "violencia de género", "violencia doméstica", "autoconciencia de los malestares del cuerpo", "autoconciencia del malestar que no tiene nombre", la obra de Arendt es objeto de una crítica profunda y pormenorizada. No solo se le ha criticado por negar carácter político al entramado de relaciones de poder y de violencia, ejercidas en el espacio de lo doméstico y de lo familiar, sino también por su concepción de "lo social”. De lo social como dimensión humana que compartimos con otras especies animales y, por ello, quedar devaluada e infravalorada en su concepción filosófico-política. Y de lo social como esfera o espacio emergente en el siglo XVII. Mientras que para Arendt lo social vino a difuminar la barrera de lo privado y de lo público, tan admirada y valorada en su análisis, para las feministas lo social es un espacio que abre las puertas a las mujeres en los Salones, primero, con el Preciosismo y, posteriormente, al movimiento social Sufragista. 


\section{EL CUERPO Y EL SUFRAGISMO}

\subsection{DISCURSOS Y REALIDAD}

Las ventajas que supuso la construcción de la sociedad civil, para los individuos o grupos minoritarios con capacidad de apelar o recurrir, para exigir que se cumplieran los derechos naturales, tuvieron sus contrapartidas, las cuales restaron posibilidades de avanzar hacia la consecución de sus metas a un paso más ligero. El siglo que vio nacer al Sufragismo conoció otros cambios en otras esferas e instancias de la sociedad: unos eran relativos a nuevas realidades; otros fueron reacciones a las nuevas concepciones liberales, libertarias, socialistas, etc. y feministas. Destacaremos el auge y proliferación de las ciencias y las reacciones de las confesiones religiosas ante los cambios y nuevas visiones del mundo que, cada vez más, cobraban un notable protagonismo.

$\mathrm{Si}$, en el espacio de lo social, como miembros de la sociedad civil, las manifestaciones sufragistas son un icono paradigmático de su tiempo, sobre todo realzado por los derroteros por los que caminó el mundo, hay otra imagen que responde a una nueva creación de la época: los desfiles de la moda y el invento de las mujeres-maniquíes. Mientras Napoleón III reestablece, en 1851, el sufragio universal masculino en Francia, eliminado por la Asamblea Nacional el año antes, y excluye a todas las mujeres del derecho al voto, C. F. Worth, el modisto de su esposa -Eugenia de Montijo-, inventa las pasarelas de la moda. Se generan, pues, dos iconos paradigmáticos de la época y de lo que vendrá después: los cuerpos femeninos desfilando para mostrar las ropas femeninas de la moda en París y las seguidoras del manifiesto de Séneca Falls en Estados Unidos, primero, y en Gran Bretaña un poco más tarde, exigiendo Votes for Women, desfilando clandestinamente por las calles, mostrando la ilegitimidad de la exclusión de los derechos de ciudadanía y del espacio de lo político.

La mecanización de las industrias textiles y la bajada de los precios de las telas de algodón, sector en el que trabajaban esclavos y esclavas en los Estados Unidos, nos pueden ayudar a comprender, en parte, el inaudito auge de la ropa interior femenina en el siglo XIX. Los estudios sobre la época expresan que la preocupación por envolver y tapar el cuerpo es casi "enfermiza". Hay una obra de arte paradigmática de esta mentalidad emergente: Madame Récamier de J.L David, que "encarna la castidad depurada del ideal femenino" que, paulatinamente, se va imponiendo desde principios de siglo, el cuerpo femenino totalmente vestido (Knibiehler, 2006: 343). En el feminismo del siglo XIX existe la conciencia de que se ha generado una tiranía de la moda: primero, en la oposición al uso del corsé por constreñir el cuerpo, como ya lo denunciara Flora Tristán en su obra en la década de los años treinta. Y un poco más adelantado el siglo, se llega a proponer una reforma de la vestimenta en el marco de la lucha por la libertad del cuerpo. En Estados Unidos se crea la Free Dress League en 1878, que tendrá una notable influencia.

Del mismo modo que la industrialización había contraído nuevas realidades que configuraban de un modo particular la vida de las mujeres, existía otra preocupación en la época que incitaba a la creación de ligas neomalthusianas, las cuales contribuyeron notablemente a la difusión de métodos anticonceptivos para frenar el crecimiento 
geométrico de las poblaciones. Tales grupos neomalthusianos comenzaron a tener en la década de los años setenta una presencia pública que acarreó problemas a sus protagonistas, dado que el terreno en el que trabajaban era muy hostil. Se produjo un auge de los discursos científicos que definían a las mujeres como seres asexuados. Si el discurso científico se opuso, en aspectos muy relevantes a los discursos teológicos, en las definiciones sobre las mujeres se generaron confluencias entre ambos que redundaron en la identificación de sexualidad femenina y reproducción. El feminismo, particularmente el Sufragismo, no fue ajeno a estas influencias. Ello explica que la abstinencia o continencia sexual sea una propuesta muy aplaudida entre sectores muy amplios, incluso feministas. Los consensos alcanzados para controlar el índice de natalidad se debieron fundamentalmente a una representación de la sexualidad femenina muy específica, que no consistió precisamente en la separación de placer sexual y fin reproductivo sino en la identificación de sexualidad y maternidad. El derecho natural a la propiedad, proclamado por el liberalismo político, tuvo una interpretación singular en torno a esta problemática: en Estados Unidos, los grupos denominados Moral Education Societies, creados en los años setenta, propagan la importancia de la self-ownership, la propiedad de sí misma, y la racionalización del deseo sexual.

La exhortación a la racionalización del deseo femenino venía a reforzar una realidad contra la que tuvieron que empezar a luchar las primeras mujeres médicas: en 1845, Elisabeth Blackwell, primera mujer médica de Estados Unidos, afirmaba que la frigidez es producto de una educación en la que se le enseña a las niñas que pensar en el sexo es pecado (Knibiehler, 2006: 356). Los grupos neomalthusianos que no coincidieran en defender el control de la natalidad de las poblaciones, mediante la abstinencia, tendrían un largo recorrido para que sus propuestas fueran aceptadas: Annie Besant, de la Liga malthusiana inglesa, fue detenida en 1877 por publicar un libro sobre métodos anticonceptivos (Käppeli, 2006: 539). Estas primeras mujeres, que lucharon solas en estos frentes, realizaban su trabajo en un sistema en el que funcionaban los llamados por Michel Foucault dispositivos de saber-poder: la ovología, en pleno auge entre 1840 y 1860, establece que el goce femenino no es necesario para la fecundación. A todo ello sumadas las enfermedades venéreas de las que eran víctimas las mujeres, hasta el extremo de desconocer en muchas ocasiones que las padecían: creían que la metritis era inevitable y universal, la sífilis, muy extendida, era padecida en numerosas ocasiones sin que la esposa lo supiera puesto que el médico no se atrevía, sin la autorización del marido, a revelar la enfermedad, porque el tratamiento delataba que el esposo tenía relaciones sexuales extramatrimoniales, muchas veces contagiados en los burdeles.

La medicina decimonónica trabajaba con la creencia de que todas las mujeres son nerviosas, lo han sido o lo serán. La histeria es la enfermedad que algunos consideraron inherente a la naturaleza femenina. En el proyecto inicial de escribir la Historia de la Sexualidad, Michel Foucault pensaba titular el cuarto volumen La Mujer, la Madre y la Histérica, donde trataría de la formación de una experiencia de la sexualidad de las mujeres a partir de la histerización del cuerpo femenino, realizada desde diversas instancias en el curso de los siglos XVIII-XIX. En el esbozo que Foucault hizo de la investigación, que no llegó a redactar por su prematura muerte, expone que el sexo 
femenino adquirió una relevante importancia desde el punto de vista médico-social. En este contexto en Europa, y particularmente en Francia, se llevaron a cabo grandes intervenciones quirúrgicas con las muchachas y afirma que "la cauterización clitoridiana con hierro al rojo vivo era, si no corriente, por lo menos relativamente frecuente en la época” (Foucault, 1985 : 153).

Los técnicos -médicos y legisladores- iban adquiriendo cada vez más poder sobre la población, en detrimento de la autonomía de los/as miembros de la sociedad civil. Hacia mediados del siglo XIX comenzaron a endurecerse las regulaciones legales antiabortistas tanto en Europa como en Estados Unidos. La mayoría de ellas estipulaban castigos para las mujeres y para quienes practicaban abortos. A principios de siglo, las legislaciones que estuvieron vigentes en Gran Bretaña y en Estados Unidos respetaban el tiempo que precede al quickening, definido éste como "el momento en que las mujeres sentían palpitar la vida en su seno, a unos tres o cuatro meses de embarazo" (Walkowitz, 2006: 410). En estas leyes se veía la preocupación por el peligro de los abortivos para la salud femenina. Las reformas legales posteriores comienzan a enfocar el aborto desde el punto de vista del derecho penal, sin hacer referencia al quickening, por considerarlo impreciso y no fundado en el saber médico. El conocimiento que cada mujer embarazada tenía de su propio cuerpo no sólo se infravaloraba, sino que se llegó a anular, por ser considerado un conocimiento de poca precisión. En Estados Unidos comienza una campaña contra el aborto a mediados de siglo y, concretamente, la American Medical Association lanzó una enfocada a distintos sectores de la población -editoriales, asociaciones médicas,...- con el objetivo de asegurar la imputación criminal del aborto, excepto en el caso de que hubiera que salvar la vida de la madre.

\subsection{LA DOBLE GENEALOGÍA SUFRAGISTA: CUERPO, ACCIÓN Y DISCURSO}

La figura de la madre y la maternidad de las mujeres fue el nexo que posibilitó el diálogo del Sufragismo con su época. Si no hubiera existido en el código de la época un elemento de intersección -que en el caso que nos ocupa fue la veneración de la función maternal de las mujeres- la historia se hubiera contado de otra manera. Ante la compleja realidad de una época que caminaba hacia el futuro, pero que tenía que conciliar las reacciones de quienes no querían romper con la tradición y todo lo que ello implicaba, en el Sufragismo se encuentran dos posiciones muy distintas con respecto a las concepciones del cuerpo femenino. Como veremos, hay una doble genealogía con respecto a la concepción de la libertad y el cuerpo de las mujeres en el Sufragismo, que cobra sentido en base a la dicotomía generada entre planteamientos proteccionistas y planteamientos vindicativos.

Los planteamientos vindicativos corrieron de la mano de las Hermanas Claflin, Victoria ClaflinWoodhull y Tennessee Claflin. En 1870 iniciaron la publicación de la revista Woodhull\&ClaflinWeekly. Entre sus publicaciones destacan los temas referidos a las enfermedades venéreas, el aborto, la sexualidad femenina, tratados desde un enfoque vindicativo: se planteaba la autonomía del cuerpo de la mujer de una forma muy novedosa en el siglo XIX. La defensa de los derechos naturales de las mujeres - 
derecho a la propiedad de su cuerpo y derecho a la libertad de su cuerpo- fueron defendidos de una manera radicalmente nueva; como hemos descrito la moral dominante proponía la abstinencia sexual como la regla de oro para proteger a las mujeres en la sociedad patriarcal.

Las Hermanas Claflin eran partidarias del socialismo y del amor libre. Entre las críticas que el Sufragismo recibía para ser socialmente desacreditado destacaba el denunciar que las mujeres que exigían el derecho al voto eran partidarias del "amor libre”. Este hecho motivó que cuando en 1871 las Hermanas Claflin asistieron en Washington a la apertura de una convención de la National Woman Suffrage Association no fueran muy bien recibidas. En 1872 Victoria ClaflinWoodhull pidió el voto, en otra convención sufragista, para una candidatura que presentaron a la presidencia de los Estados Unidos. El apoyo que se pedía fue denegado. Hay dos contribuciones notabilísimas que debemos a las Hermanas Claflin: su acción simbólica -cuando el sufragio universal era sólo masculino- de presentar una candidatura encabezada por una mujer a la presidencia de los Estados Unidos, y el desafío a la creencia decimonónica de que las mujeres son seres asexuados.

Entre las sufragistas que denegaron el apoyo a las Hermanas Claflin se organizó para el día de las elecciones de 1872 otra acción de desafío a las leyes establecidas y que, por tanto, era ilegal: un grupo de cincuenta mujeres acudieron a depositar su voto en las urnas. Por esta acción Susan Anthony, muy conocida por su participación en sentadas y otros actos públicos, fue procesada. Anthony era una destacada activista desde que tenía veintiún años: en 1848 promovió una campaña de recogida de firmas para realizar una petición a la Asamblea Legislativa, exigiendo la revisión de lo que se había legislado sobre el derecho de propiedad de la mujer casada, considerado en el escrito de apelación extremadamente restrictivo.

Susan Anthony escribió un texto con Elizabeth Cady Stanton, leído en la Asamblea Legislativa del Estado de Nueva York, en el que se expresa cómo el cuerpo constituye un primer dato para la exclusión social y política que este movimiento combatía: "La piel del negro y el sexo de la mujer son ambos una evidencia prima facie de que uno y otro fueron destinados a estar sometidos al hombre blanco de origen sajón”(Martín-Gamero, 2002: 63). El hecho de que los hombres negros consiguieran el derecho de voto antes que las mujeres, y el hecho de que no sufrieran la exclusión de oficiar en el altar y, por tanto, no sufrir la exclusión en la Iglesia, eran muestras evidentes para las Sufragistas de que el prejuicio contra el sexo estaba más arraigado que el prejuicio contra las personas de color.

Para comprender en toda su extensión al Sufragismo subrayaremos que la práctica de la desobediencia civil en este movimiento social no se dio sólo frente a las leyes del código civil, sino también contra las leyes del código penal y las establecidas en el derecho canónico. Esta ampliación de la desobediencia a las leyes, consumada por el Sufragismo, impregna a este movimiento social de una peculiaridad histórica sin parangón, ni en su época ni en el imaginario del siglo XXI que avala con onomásticas al referente más importante de la desobediencia civil en el mundo global: Ghandi. 
La crítica al derecho canónico estaba plasmada en la Declaración de Séneca Falls de 1848. En esta Declaración no solo se denuncia la exclusión del Estado y de sus diversas instituciones públicas, sino también la exclusión y marginación que afectaba a las mujeres en la Iglesia. La condición subordinada en la Iglesia era considerada como consecuencia de una lectura tergiversada de las Sagradas Escrituras. Por ello, entre sus decisiones figura una muy importante: "Que la igualdad de los derechos humanos es consecuencia del hecho de que toda la raza humana es idéntica en cuanto a capacidad y responsabilidad” (Martín-Gamero, 2002: 51). Se remiten al Antiguo Testamento donde, según su exégesis, se declara la creación simultánea del hombre y de la mujer. Y remitiéndose a la recepción de tal pasaje en el Nuevo Testamento apelan a las palabras de Pablo cuando habla de la Igualdad como el auténtico espíritu del cristianismo. Tales datos son esgrimidos para criticar la posición subordinada que la mujer ocupaba en las Iglesias.

Dado el enfoque hacia una crítica de la alianza de Estado e Iglesia, y de la subordinada situación de las mujeres tanto en las jerarquías eclesiásticas como en las prescripciones morales de las iglesias cristianas, un grupo de mujeres sufragistas y escritoras deciden estudiar la Biblia, bajo la coordinación de E. Cady Stanton. En el grupo había helenistas y hebraístas, y se dedicaron a la traducción y el significado en los textos originales de todos los pasajes que hablan o se refieren a mujeres. En el Antiguo Testamento consideran que está el primer título de propiedad, dado de igual modo a mujeres y a hombres. Con respecto a lo establecido en el derecho canónico y en el derecho civil, no encuentran ni una palabra en la que se establezca el dominio del hombre sobre la mujer. Destacaremos que no aparece ningún comentario sobre un pasaje transcrito que hace referencia al desnudo sin sentimiento de vergüenza, precisamente porque la situación descrita era matrimonial: "Y estaban ambos desnudos, el hombre y su mujer, y no sentían vergüenza” (Cady Stanton, 1997:49). Este pasaje pertenece al primer capítulo del Génesis, donde también se define a la mujer como Varona, la madre de la especie, hombre con útero, con el significado de la raíz lingüística de woman, Wob-man (wob: útero, man: hombre). Y se afirma en $L a$ Biblia de la mujer: "Ella era hombre y más que hombre gracias a su maternidad" (Cady Stanton, 1996: 51). Asimismo se defiende la supremacía de la mujer en la relación marital expresada en los textos sagrados hebraicos y, luego, cristianos; la madre era la cabeza de familia y del hogar, hechos interpretados como reflejo de que las sociedades primitivas eran matriarcales.

No solamente se ha significado el desnudo femenino, y se ha resignificado el útero en la moral cristiana Sufragista, sino que también se aborda la cuestión del velo, prenda de vestir femenina que tapa el cuerpo, incluida la cabeza. A propósito del pasaje en el que se ven por primera vez Isaac y Rebeca, en que ella se baja del camello y se cubre con el velo, se rememoran distintas sociedades que han conocido la tradición del velo. Se considera que la opinión de los comentaristas masculinos, que expresan que el velo es una evidencia del sometimiento de la mujer, es una interpretación interesada y errónea. Los argumentos en contra se basan en rememorar las diversas sociedades en las que el velo ha tenido un significado ritual más que opresor: Rusia, Turquía... Que el velo no es un síntoma o signo de humillación de la mujer es defendido con argumentos que ponen de manifiesto que son las mujeres las que deciden ponérselo para 
protegerse: "En todos los casos el velo parece haberse usado para proteger a la mujer de una intrusión prematura o inoportuna, y no para señalar su posición humillada. El velo es más bien un reflejo de los hábitos y pensamientos de los hombres que un símbolo de inferioridad para las mujeres” (Cady Stanton, 1997: 77).

En el Sufragismo británico las prácticas de desobediencia civil llegaron a su culmen. Entre los métodos utilizados para presionar al gobierno se llevó a cabo una implicación muy profunda, utilizando el propio cuerpo como un arma: la huelga de hambre. En 1913, en Inglaterra más de mil mujeres habían pasado por las cárceles acusadas por acciones ilegales, todas ellas públicas. La huelga de hambre fue practicada por un porcentaje muy elevado de sufragistas en Gran Bretaña, viéndose el gobierno británico obligado a la alimentación forzosa y a permitir que el cumplimiento de las penas fuera escalonado (Anderson y Zinser, 1991: 410 y ss.). Con respecto al cumplimiento de las penas en las prácticas de desobediencia civil, el Sufragismo tiene un papel histórico innovador. La figura de Emmeline Pankhurst es reveladora: sus escritos y posiciones son ejemplares frente al conocido O. W. Holmes y a la tradición de Realismo legal. HannaArendt califica de absurda a esta doctrina en el terreno del Derecho Penal. La posición que se defiende es que el pago de la pena justifica la violación de la ley, como si el homicidio, la violación o el incendio provocado pudieran justificarse porque sus operadores estuvieran dispuestos a cumplir el castigo (Arendt, 1999: 75).

E. Pankhurst fue una destacada líder británica de las conocidas como suffragettes, nombre que recibían las sufragistas militantes para diferenciarlas de las suffragists, que integraban la Society of Woman Suffrage y no eran activistas. Las suffragettes, a juzgar por los relatos de la Historia y por la obra de E. Pankhurst es el ejemplo más claro de la difícil lucha que supuso el Sufragismo para las mujeres. Aunque a finales del siglo XIX se había conseguido el derecho de voto en las elecciones municipales, la lucha por el reconocimiento total de ese derecho llevó hasta el extremo los métodos de desobediencia civil, declarándose pacifistas y contrarias a atacar la vida humana de sus contrincantes. Se definían pacifistas y las vidas que arriesgaron fueron las suyas propias. El sufragismo militante británico señaló como blanco prioritario de ataque en sus acciones la propiedad del Gobierno. No sólo eso sino que alentaban a acciones tales como, por ejemplo, la ocupación de la Cámara de los Comunes, resistiendo hasta el extremo ante la acción de expulsión de la misma por parte de la policía. La Women's Social and PoliticalUnion (W.S.P.U.), bajo el liderazgo de E. Pankhurst, no aceptó nunca justificar sus acciones ilegales con el pago de la pena. Las palabras de E. Pankhurst son una muestra de una de las señas de identidad más importante de la desobediencia civil feminista: "Pero mi última palabra es para el Gobierno: ¡Yo incito a esta asamblea a la rebelión...Detenedme, si os atrevéis, y si es que os atrevéis, os advierto que no me meteréis en la cárcel...” (MartínGamero, 2002: 141).

Cabe destacar que, si bien el Sufragismo británico comprendió la perversidad que podía conllevar el planteado por el Liberalismo Derecho a la Propiedad, conservaron, malgré finalizado el siglo XIX, un sesgo de la concepción de las mujeres como seres asexuados y, por tanto, eran alentadas a protegerse de las miradas masculinas. La 
propia hija de Emmeline Pankhurst, Christabel Pankhurst, lo expresa explícitamente: a fin de evitar ser acusadas de poco femeninas, las sufragistas, excepto en la lucha, mantenían los convencionalismos en todo (Martín Gamero, 2002: 141-143). Y ello también se reflejó en sus acciones: el desnudo femenino de la obra de Diego Velázquez, La venus del espejo, de la colección del Museo Nacional de Londres, fue objeto de un atentado con tijeras hasta quedar bastante partido el lienzo, perpetrado por una sufragista de origen canadiense afincada en Londres. Emilia Pardo Bazán, considerándolo una acción injustificada, publicó un escrito en el que criticaba la doble vara de medir que se puso de manifiesto con los innumerables ataques que recibió por parte de la crítica masculina, comparándolos a otras acciones de carácter violento que eran habituales en las luchas coetáneas de principios de siglo XX en Europa (Pardo Bazán, 1999: 298-300). De cualquier modo, lo que se ponía de manifiesto era que el desnudo femenino era percibido por las sufragistas inglesas de la misma forma que sus compañeras estadounidenses que escribieron La Biblia de la Mujer. Quedaría mucho tiempo para que las mujeres no introyectaran la mirada de los Otros en sus propias reglas de conducta. Las reivindicaciones para la libertad del cuerpo desnudo quedaron pendientes para las siguientes Olas de feminismo.

\section{CUERPO, ACCIÓN Y DISCURSO EN EL SIGLO XXI}

El derecho natural a la propiedad, tan diversamente interpretado en la época del Sufragismo es, de nuevo, núcleo tanto de los discursos como de las prácticas de desobediencia civil de las mujeres contra una realidad privada, social y política que las oprime. El Sufragismo nació y se desarrolló en un contexto histórico en el que los discursos vindicativos sobre el cuerpo de las mujeres eran muy minoritarios. La llamada moral victoriana, la consideración de las mujeres como seres asexuados y la identificación de cuerpo y sexualidad femeninos con la maternidad son las características más sobresalientes de las visiones hegemónicas. Estos sesgos profundamente ideológicos de la mentalidad de la época fueron reforzados y reinterpretados, como hemos visto, por los discursos religiosos y laicos, científicos y políticos.

Al analizar las prácticas de desobediencia civil feministas hoy, sobre todo las prácticas grupales en las sociedades democráticas, hemos de tener en cuenta las diferencias fundamentales con el Sufragismo. Este fue un movimiento muy amplio, ideológicamente heterogéneo, que centró su lucha en conseguir el derecho al voto. Las acciones que llevaron a cabo, como iniciativas legislativas y otras tantas, se enfocaban a presionar al gobierno de su país porque era tal o cual gobierno el que tenía que tomar la decisión de reconocer el derecho de voto. Hubo convenciones internacionales y conocían muy bien qué era la solidaridad, y la ejercieron no solo con la causa sufragista sino también con la abolicionista. En la actualidad, aunque corresponda a los gobiernos tomar decisiones, la dimensión internacional de cualquier problema es distinta porque el contexto hoy es un mundo global. La realidad privada, social, cultural y política cuenta con unos referentes que, si bien no son ajenos a las reminiscencias que quedan de aquella etapa de la segunda mitad del siglo XIX y primeras décadas del siglo XX, conllevan un imaginario nuevo. 
En el nuevo imaginario subrayaremos tres de los referentes que lo co-forman: la revolución sexual que comenzó en la década de los años sesenta del siglo XX, las suscripciones gubernamentales a la Declaración Universal de los Derechos Humanos de 1948 y el avance en las nuevas tecnologías de la información y de la comunicación. La revolución sexual ha sido criticada por la Ola de feminismo que se extiende con el Mayo del 68 francés, por ser androcéntrica y reproducir con discursos pseudoliberadores nuevas formas de sujeción de los cuerpos femeninos. La DUDH es la referencia fundamental para medir si las políticas, concepciones teóricas o prácticas privadas y públicas homologan a las mujeres con lo considerado "lo humano" por antonomasia. Las TIC hacen referencia a un nuevo espacio que no es exactamente ni el privado, ni el doméstico, ni el social ni el político. Internet, la Red, es un nuevo espacio en el que hay que aprender a cuidarse y a moverse, a navegar, bien sea de forma individual o de forma relacional.

\subsection{FEMEN: CUERPO Y ESCLAVITUD FEMENINA}

Femen es una organización feminista que nace en Ucrania, y para sus miembros fue decisiva la lectura y el estudio de la obra La mujer y el socialismo de August Bebel, porque en su pensamiento encontraron las bases teóricas del rechazo a la religión, al capitalismo y al machismo. En una de sus primeras reuniones asumen una de sus luchas más encomiadas, recogida en la afirmación Ucrania no es un burdel. Con Femen comenzó la lucha contra la industria del sexo que, con ayuda del gobierno, ha sido impulsada en su país.

Las ideas contenidas en la obra de Bebel respecto a la religión, y su experiencia propia de la iglesia ortodoxa en Ucrania y en Rusia, les llevan a sostener que la religión es un instrumento del patriarcado destinado a dominar a la mujer. El clericalismo, tanto cristiano como musulmán, es objeto de rechazo y de crítica rotunda para las activistas del movimiento de desobediencia civil feminista más conocido del siglo XXI. Critican a la iglesia ortodoxa, renacida tras la etapa soviética, por ponerse al servicio del Estado, así como la connivencia del clero con los regímenes corruptos. Además, se posicionan contra el uso de prendas de vestir femeninas prescritas por el hiyab que cubren el cuerpo de las mujeres en Europa.

Femen sostiene que en el mundo del siglo XXI las mujeres son esclavas porque carecen del derecho a la propiedad y, sobre todo, a la propiedad de su propio cuerpo. Las referencias de sus tesis van más allá del terreno acotado por un Estado o Gobierno: el feminismo ha denunciado que en el planeta Tierra las propiedades de las mujeres ascienden a un total de un exiguo tanto por ciento. Y, en otro sentido, las mujeres no son propietarias de su cuerpo por influencia de poderes de distinta índole, que actúan en diferentes órdenes y culturas: desde los reglamentos vestimentarios en el mundo islámico hasta la ultracosificación de los cuerpos femeninos en la industria del sexo.

En la línea del análisis del Feminismo Radical de los años setenta del siglo pasado, Femen entiende que el Patriarcado es un sistema que controla el cuerpo de las mujeres y que las medidas necesarias para abolir dicho control son: que la mujer tome las riendas de su sexualidad y que se proclame dueña de su propio cuerpo a través del desnudo. El desnudo femenino es la nueva estética propuesta para la revolución que 
consideran necesaria. En sus acciones muestran sus cuerpos-pancartas porque entienden que sus cuerpos son sus armas, denominando al conjunto de sus tácticas sextremismo. El icono del sextremismo son los pechos desnudos y las coronas de flores. Como Galia Ackerman expresa "En lugar de optar por el terrorismo, las Femen, radicales en lo más profundo, han encontrado un medio con el que atacar a sus enemigos que es al mismo tiempo lúdico y simbólico: un cuerpo desnudo en vez de una bomba o un fusil” (Ackerman, 2014: 19).

Para Femen los pilares del patriarcado son las dictaduras, la industria del sexo y las Iglesias, y sus acciones van dirigidas contra tales pilares. Son conscientes de que vivimos en la etapa del espectáculo y en sociedades en las que domina la industria de la diversión, al mismo tiempo que asistimos a un aluvión constante de sobreinformación. Ello explica que sus acciones sean performances con mensajes precisos con el objetivo de causar impacto y hacer llegar el mensaje. Ente sus objetivos está el derrocamiento de todos los regímenes dictatoriales $\mathrm{y}$, fundamentalmente, los Estados islamistas teocráticos, por imponer la Sharia y otras formas de sadismo.

\subsection{FEMINISMO, ISLAM Y DESOBEDIENCIA CIVIL}

Del mismo modo que la Biblia, el Corán tiene una historia, la historia de sus interpretaciones. Según Roger Garaudy, el literalismo es una forma incorrecta de leerlo, y como tal es una perversión que alimenta la creencia de que la fe en el Corán consiste en la fidelidad y obediencia a la forma cultural de una época o etapa histórica superada (Tamayo, 2012: 122). Entre las lecturas ilegítimas del Corán se señala la que radica en el culto idolátrico a la tradición, porque conlleva prácticas contrarias al propio mensaje del Corán. Entre los casos que ejemplifican esta lectura perversa se cita la condición inferior de la mujer. Por el contrario, se argumenta que en los textos sagrados de la religión musulmana se reconoce igual dignidad al hombre y a la mujer, que la nueva exégesis no androcéntrica comprueba que el Corán es un texto que incluye a hombres y a mujeres (Tamayo, 2012: 123).

El debate en el Islamismo estriba en si la Ley Islámica contenida en el Corán, la Sharia, prescribe la igualdad o la desigualdad entre hombres y mujeres. Quienes defienden que está prescrita la desigualdad generalmente interpretan que las mujeres son propiedades o bien del padre o bien del marido. Entre quienes defienden que el Corán no prescribe la desigualdad entre hombres y mujeres, hay una corriente muy extendida que para explicar por qué deciden llevar velo y taparse parcial o totalmente el cuerpo, incluida la cabeza, recurre a razones místicas o ascéticas. Los argumentos místicos y ascéticos estriban, respectivamente, en apelar a la relación con Dios, sin intermediación, y a evitar sufrimientos cuyo origen es externo al Corán, pero las pautas generales de la tradición vestimentaria siguen siendo obedecidas.

La historia de las luchas de las mujeres en los regímenes teocráticos islamistas es casi imposible de narrar por su corta vida. Un ejemplo es el feminismo en Irán, después del triunfo de la revolución islámica de 1978 y la subida al poder de Jomeini. El primer 8 de marzo en que Jomeini estaba en el gobierno las mujeres se manifestaron públicamente, y entre sus protestas estaba la negativa a llevar chador, prenda de calle típicamente iraní, que cubre todo el cuerpo excepto la cara. Destacaremos que una de 
las primeras medidas del gobierno islámico fue la implantación del hiyab, código vestimentario islámico. Después de las manifestaciones de marzo de 1979 la represión alcanzó cuotas tan altas que se llegó a la desmovilización de la oposición al régimen.

El seguimiento de las pautas del hiyab es tan fuerte en la cultura islámica que la desobediencia civil propiamente dicha se da frente a las leyes de los Estados laicos, como es el caso de Turquía. La República turca prohibió el uso del velo o pañuelo islámico en todos los lugares públicos oficiales, incluida la Universidad. De las movilizaciones públicas más trascendentes, a nivel internacional, de las mujeres islámicas es la protesta contra el gobierno laico turco y su reglamentación vestimentaria. Entre las explicaciones ofrecidas sobre este fenómeno abundan las que argumentan la fuerza de una nueva ola de islamismo fundamentalista, pero la pregunta clave es por qué los hombres fundamentalistas islámicos no salen a manifestarse en público vestidos con fez. Muchos hombres musulmanes fueron arrestados en los primeros años de la dictadura kemalista por llevar fez, siendo exhortados a llevar sombrero, símbolo occidental. Algunos de los dirigentes religiosos que predicaron en contra del sombrero fueron ahorcados (Romero Pérez, 2007: 271).

Nuestra hipótesis es que el reestablecimiento del hijab es un hecho que afecta y parte de las mujeres, y posiblemente los argumentos que se basan en la defensa de una libertad interior sea necesario explicarlos, nuevamente, desde el modelo de la mística y de la ascética. Tales argumentaciones son más de carácter ético que político, y una vez más nos vemos obligadas a rememorar la historia y a recordar que la ética es refugio cuando la política, en el menos malo de los casos, ni protege ni cuida a su ciudadanía. El movimiento de mujeres islamistas, en la década de los años ochenta en las universidades turcas, reivindicaba el uso del pañuelo, prohibido por el Kemalismo en todos los lugares oficiales. Sin menospreciar la política del Feminismo de Estado en la Turquía laica, tenemos que tener en cuenta lo señalado por la socióloga Serif Mardin: la falta del Estado en desarrollar instrumentos para facilitar la realización de derechos garantizados para la mayoría, forma la base de una dinámica social en la que la gente se aproxima a la religión en orden de desarrollar estrategias para hacer frente a la vida. Por otra parte, el kemalismo introdujo el corsé para quienes conocían la comodidad de la vestimenta otomana; o entendieron que la modernización de Turquía pasaba por participar en los concursos de misses mundiales. No es de extrañar, por tanto, que los discursos de las mujeres islamistas que se han organizado en movimientos sociales reivindicativos argumenten en contra de la utilización occidentalista del cuerpo femenino. La introducción del cuerpo humano en el ámbito de la ciencia y de la secularización supone un control estético y médico. Ellas expresan que prefieren el cuerpo musulmán, que vive al ritmo de una disciplina impuesta por la moral y por la fe (Góle, 1991: 99 y ss.).

Femen ha realizado acciones en varios países protestando contra el velo llevado por mujeres musulmanas. Denuncian que los islamistas obliguen a sus hijas a llevar velo a una muy temprana edad, a los once o doce años, y en Afganistán a las niñas se las cubre con seis años. Las niñas y jóvenes musulmanas están acostumbradas a ir tapadas y no conocen la libertad del cuerpo. Femen sostiene que es tan falso hablar de la libertad de llevar velo como de la libertad de trabajar como prostituta y, por ello, 
exigen que el nicab se prohíba hasta los dieciocho años. Desde Femen se entiende que encerrar el cuerpo en un saco informe es un símbolo de la esclavitud impuesta por los hombres a las mujeres, ya sean padres, maridos, hermanos o imanes. Como se reservan llevar a cabo acciones en países con dictaduras han elegido Turquía, Francia y Reino Unido para protestar contra el hiyab. En este último manifestaron su oposición a la decisión del Comité Olímpico para los Juegos de Londres de 2012: se autorizó participar a las mujeres musulmanas con sus ropas tradicionales. Se criticaba que permitieran participar a países que lapidan a mujeres y les inflingen castigos corporales.

La actitud para con el velo islámico está cambiando a favor de un supuesto respeto al derecho a llevarlo: no sólo en Turquía se suprimió la legislación que lo prohibía en todos los lugares oficiales sino que también ha habido reformas legales en Alemania. El Tribunal Constitucional alemán sentenció en el mes de marzo que la prohibición del velo islámico en los lugares públicos, la cual afectaba a maestras alemanas, no es compatible con la Ley Fundamental germana. Alemania es uno de los países europeos con mayor presencia musulmana: tres millones cuatrocientos mil habitantes practican la religión. El Islam forma parte de Europa y el fenómeno conocido como Euroislam obliga a reconocer que no se trata sólo de una realidad numérica sino también cultural, religiosa y política.

\section{CONCLUSIONES: SOBRE CUERPO Y REPRESENTATIVIDAD EN LA DEMOCRACIA DEL SIGLO XXI}

Como hemos tenido la ocasión de ver, la desobediencia civil feminista ha tenido un papel determinante en la subsanación de la infrarrepresentatividad de las minorías en la historia de las democracias modernas. Por ello, creemos que hay razones para plantear que, aunque parezca contradictio in terminis, la desobediencia civil debería estar regulada por el Derecho como una de las maneras posibles de mantener asegurada la representatividad de las minorías. Y para ello, es muy importante que se comprenda que el Sufragismo es el movimiento de desobediencia civil paradigmático: no solamente porque consiguió que la mitad de la población excluida accediera al espacio de lo político, sino también porque en su seno se planteó que el no respeto a las leyes injustas no debería conllevar el cumplimiento de la pena.

Por otra parte, hemos visto la importancia que tiene que un movimiento social pueda encontrar un referente común con sus contrincantes, es decir, sitúe y señale una autoridad externa a las distintas partes en liza, a la que se pueda apelar o, simplemente, remitirse. En la historia occidental hemos visto que los textos sagrados -La Biblia- y las distintas interpretaciones sobre ellos han desempeñado un rol histórico innegable. Nos permitimos pensar que, por analogía, las nuevas exégesis sobre el Corán también están desempeñando un papel importante dentro de la comunidad musulmana. Pero, dicho esto, ahora tenemos que ver dónde buscar esa autoridad externa a la que todas las partes podamos remitirnos para el encuentro entre culturas distintas. O, dicho de otro modo, cómo encontrar la vía de diálogo liberador para quienes defienden cubrir sus cuerpos y quienes defienden que la solución es el desafío del desnudo. 
La auténtica autonomía no radica ni en el aislamiento ni en introyectar las miradas de los Otros. La historia nos ha enseñado que la autoconciencia del propio cuerpo es escuchar los malestares y no quedarse con ellos, sino aprender el origen y objetualizarlos para combatirlos. De ahí que el concepto de autoconciencia, aportado por el feminismo de los setenta a la teoría política, no deba ser olvidado ni mucho menos la implicación de los malestares del cuerpo que no tienen nombre, y que son todos previos a la autoconciencia. Tales malestares no deben resolverse sólo desde posturas éticas -recluyéndose en la mística o en la ascética. El término autoconciencia para el feminismo es la condición que posibilita comprender y asumir la dimensión social y colectiva de los problemas personales.

En el complejo mundo en el que estamos, donde los cambios se dan a un ritmo vertiginoso, el referente común entre mujeres de distintas culturas son los Derechos Humanos y la historia que nos precede, el reconocimiento de nuestra genealogía compartida. En este sentido, podemos aprender mucho de las Sufragistas, quienes en un mundo en el que proliferaba el darwinismo social para fragmentar a la especie humana, ellas defendieron la existencia de una única raza. Y el objetivo por el que lucharon es una conquista universal: recojamos pues este antecedente común y trabajemos por cuotas de mayor democracia, ya que es ése el pasado que nos une.

\section{REFERENCIAS BIBLIOGRÁFICAS}

ACKERMAN, Galia (2014): En el principio era el cuerpo. Barcelona: Calmann-Levy. Trad. Paula Cifuentes.

AMORÓS, Cèlia y DE MIGUEL, Ana (2005): Teoría Feminista: de la Ilustración a la globalización (3 vols.). Madrid: Minerva.

ANDERSON, Bonnie y ZINSER, Judith (1991): Historia de las mujeres. Una historia propia. vol. II. Barcelona: Crítica.

ARENDT, Hannah (2011): La condición humana. Barcelona: Paidós. Trad. de Ramón Gil Novales. Introducción de Manuel Cruz.

ARENDT, Hannah (1999): Crisis de la República. Madrid: Taurus. Trad. de Guillermo Solana.

CADY STANTON, Elizabeth (ed) (1997): La Biblia de la mujer. Madrid, Cátedra. Trad. de J. Teresa Padilla Rodríguez y M Ma Victoria López Pérez. Prólogo a la edición española de Alicia Miyares.

FOUCAULT, Michel (1985): Saber y verdad. Madrid: La Piqueta. Edición y prólogo de Julia Varela y Fernando Alvárez-Uría.

GÖLE, Nilüfer (1991): Musulmanas y Modernas. Madrid: Talasa. Trad. De Paulino Rodríguez.

JAGGAR, Alison (1983): Feminist Politics and Human Nature. London: Rowman \& Littlefield Publishers. 
KÄPPELI, Anne-Marie (2006): Escenarios del feminismo. En Duby, G. y Perrot, M. (dir.), Historia de las mujeres. El siglo XIX, 521-558. Madrid: Taurus. Trad. de Marco Aurelio Galmarini.

KNIBIEHLER, Yvonne (2006): Cuerpos y corazones. En Duby, G. y Perrot, M. (dir.), Historia de las mujeres. El siglo XIX, 339-388. Madrid: Taurus. Trad. de Marco Aurelio Galmarini.

LOCKE, Jonh (1990): Tratado sobre el gobierno civil. Madrid, Alianza. Trad. de Carlos Mellizo.

MARTÍN-GAMERO, Amalia (ed.) (2002): Antología del feminismo. Sevilla, Instituto Andaluz de la Mujer, col. Hypatia.

PALOMO, Eva (2015): El ecopacifismo de Sylvia Pankhurst en el entorno sufragista y socialista de principios del siglo XX. En Alicia Puleo et at. Hacia una cultura de la sostenibilidad, pp. 65-74. Valladolid: Facultad de Filosofía y Cátedra de Estudios de Género.

PARDO BAZÁN, Emilia (1999): La mujer española y otros escritos. Madrid: Cátedra.

PLATÓN (2010) :Apología de Sócrates. Madrid: Austral.

PLATÓN (2003): Diálogos. Volumen V. Madrid: Gredos.

POSADA, Luisa (2012): Sexo, vindicación y pensamiento. Madrid: Huerga y Fierro.

PULEO, Alicia (2011): Ecofeminismo para otro mundo posible. Madrid: Cátedra.

ROMERO PÉREZ, Rosalía (2007): La modernidad en la República de Turquía: laicidad y feminismos. En Amorós, C. y Posada, L. (eds.). Multiculturalismo y feminismo, pp. 271-284. Madrid: Instituto de la Mujer (Ministerio de Trabajo y Asuntos Sociales).

SÁNCHEZ, Cristina (2001): La ciudadanía de las mujeres: las hijas espúreas de Hanna Arendt. En Valcárcel, A. y Romero Pérez, R. (eds.). Pensadoras del siglo XX, pp. 45-58. Sevilla: Instituto Andaluz de la Mujer, col. Hypatia.

TAMAYO, Juan José (2010): Islam, cultura, religión y política. Madrid: Trotta.

THOREAU, Henry David (1849): Del deber de la desobediencia civil, www.editorialpi.com (julio, 8, 2012).

VALCÁRCEL, Amelia (2008): Feminismo en el un mundo global. Madrid: Cátedra.

VALCÁRCEL, Amelia, RENAU, M ${ }^{\mathrm{a}}$ Dolors y ROMERO PÉREZ, Rosalía (eds.) (2000): Los desafíos del feminismo ante el siglo XXI. Sevilla: Instituto Andaluz de la Mujer, col. Hypatia.

WALKOWITZ, Judith R. (2006): Sexualidades peligrosas. En Duby, G. y Perrot, M. (dir.), Historia de las mujeres. El siglo XIX, 389-426. Madrid: Taurus. Trad. de Marco Aurelio Galmarini. 